\section{Brazilian Journal \\ of Chemical \\ Engineering}

ISSN 0104-6632

Printed in Brazil

www.abeq.org.br/bjche

\title{
CONCENTRATION FIELDS NEAR AIR-WATER INTERFACES DURING INTERFACIAL MASS TRANSPORT: OXYGEN TRANSPORT AND RANDOM SQUARE WAVE ANALYSIS
}

\author{
H. E. Schulz ${ }^{1 *}$ and J. G. Janzen ${ }^{2}$ \\ ${ }^{1}$ Departamento de Hidráulica e Saneamento, Escola de Engenharia de São Carlos, \\ Universidade de São Paulo, Av. do Trabalhador São-Carlense 400 \\ CEP: 13566-590, São Carlos - SP, Brasil. \\ E-mail: heschulz@sc.usp.br \\ ${ }^{2}$ Universidade Federal de Rondônia, Campus de Ji-Paraná, Rua Rio Amazonas 351, \\ Jardim dos Migrantes, CEP: 78961-790, Ji-Paraná - RO, Brasil. \\ E-mail: jgersonj@gmx.net
}

(Submitted: July 30, 2008 ; Revised: February 20, 2009 ; Accepted: February 28, 2009)

\begin{abstract}
Mass transfer across a gas-liquid interface was studied theoretically and experimentally, using transfer of oxygen into water as the gas-liquid system. The experimental results support the conclusions of a theoretical description of the concentration field that uses random square waves approximations. The effect of diffusion over the concentration records was quantified. It is shown that the peak of the normalized rms concentration fluctuation profiles must be lower than 0.5 , and that the position of the peak of the rms value is an adequate measure of the thickness of the diffusive layer. The position of the peak is the boundary between the regions more subject to molecular diffusion or to turbulent transport of dissolved mass.

Keywords: Concentration boundary layer; Interfaces of gas-liquid systems; Turbulent mass transfer; Experimental interfacial transfer; LIF measurements; Random square waves.
\end{abstract}

\section{INTRODUCTION AND REVIEW}

The transport of conservative scalar quantities (dissolved mass into a liquid) across gas-liquid interfaces is a matter of increasing practical interest. Some reasons for this interest are reasonably recent, and related to global consequences of pollution. For example, the minimization of the greenhouse effect involves exchanges of mass between the atmosphere and the oceans. It is known that greenhouse gases (like $\mathrm{CO}_{2}$ ) are accumulating in the atmosphere. Their absorption by the water bodies that cover most of the earth's surface is seen as a guaranty of a possible control of the global temperature. Considering the liquid side, the most important indicator of the quality of water bodies is their dissolved oxygen content.
Dissolved oxygen guarantees the presence of complex life forms in the water and is mainly furnished by the atmosphere, crossing the air-water interface.

While the horizontal dimensions of air-water interfaces may be very large (like the oceans' surface), the vertical dimension (thickness) is usually very small, which implies in difficulties to describe their structure and to perform measurements in their interior. Mass fluxes depend on characteristics of both sides of the interface. But considering slightly soluble gases (like $\mathrm{O}_{2}$ ), their transport is controlled mainly by the liquid side. The description of the interfacial region may be then limited to the liquid phase, while the gas phase "imposes" boundary conditions. In this case, saturation concentration is assumed to prevail at the surface, the mass transfer

*To whom correspondence should be addressed 
being governed by a combination of mechanisms of molecular diffusion and turbulent advective transport in the liquid phase. It is usually assumed that molecular diffusivity is the most relevant transport mechanism very close to the surface, and that turbulent transport becomes to be relevant below this first region (Magnaudet and Calmet, 2006). Thus, an interfacial structure is assumed to exist, composed by at least two "layers", in which different relevant mechanisms act for the mass transport. Janzen (2006) and Herlina and Jirka (2008) presented experimental results for the molecular and turbulent fluxes of oxygen which support this assumption. Different studies defined the thickness of the "diffusive layer" (where diffusion effects are relevant), generally considering a priori information, usually from a pre-defined concentration profile. The terms "diffusive layer" and "boundary layer" are frequently used. Linear concentration profiles or approaches, for example, have been used since the early study of Lewis and Withmann (1924) up to more recent descriptions, like Woodrow and Duke (2002), who defined a diffusive layer thickness considering a straight line with slope equal to the gradient of the normalized concentration profile at the water surface (named here "linear thickness"). The use of exponential profiles of the normalized concentration (Chu and Jirka, 1992; Herlina, 2005) also led to the definition of a boundary layer thickness (named here "exponential thickness"). In this case, the boundary layer is taken as the distance from the surface at which the normalized concentration is $1 / \mathrm{e}$, or $37 \%$. The "linear" and the "exponential" thicknesses coincide if the profiles under analysis are really exponential. More detailed descriptions define a structure for the interfacial region composed of "inner" (closer to the interface) and "outer" (farther from the interface) layers. The turbulence conditions are taken into account and nondimensional thicknesses are furnished, involving the Reynolds $(\mathrm{Re}=\mathrm{uL} / v)$ and the Schmidt $(\mathrm{Sc}=v / \mathrm{D})$ numbers. Equations are furnished in the forms: $\delta_{1} / \mathrm{L}=\alpha_{1} \mathrm{Sc}^{-1 / 2} \mathrm{Re}_{\mathrm{s}}^{-3 / 4}$ (for the inner diffusive layer) and $\delta_{2} / \mathrm{L}=\alpha_{2} \mathrm{Sc}^{-1 / 2} \mathrm{Re}_{\mathrm{s}}^{-1 / 2}$ (for the outer diffusive layer). $\delta_{1}$ and $\delta_{2}$ are the thicknesses of the internal and the external diffusive layers, $\mathrm{L}$ is a characteristic length scale at the interface, $u$ is a characteristic velocity scale, $v$ is the kinematic viscosity, D is the molecular diffusivity of the compound being transported into the liquid, and $\alpha_{1}$ and $\alpha_{2}$ are proportionality coefficients. The influence of turbulence on gasliquid interface characteristics and mass transfer was studied considering general basic aspects (Germano, 1986; Ramshankar and Gollub, 1991; Lam and Banerjee, 1992; Zang et al., 1993; Nagoaosa, 1999;
Saylor and Habdler, 1999) and also applied to channel flows (Komori et al., 1993; Calmet and Magnaudet, 1997; Kumar et al., 1998; Handler et al., 1999). Magnaudet and Calmet (2006) present a review of studies on interfacial mass transfer, and discuss results of their own numerical simulations, related to the behavior of profiles obtained from the concentration and velocity fields, as well as conclusions that point to the adequacy of the use of the mentioned nondimensional equations for $\delta_{1} / \mathrm{L}$ and $\delta_{2} / \mathrm{L}$. Their numerical results show that the peak of the concentration fluctuation profile occurs close to the border of the outer diffusive layer. The authors mention that detailed measurements are still necessary to check all propositions about turbulent mass transfer. The concentration fluctuation profile and its peak were studied more specifically by Schulz and Schulz (1991), Momesso et al. (1997), Schulz et al. (1997), and Janzen (2006), who related the distance from the interface to the peak position to other lengths scales in the concentration boundary layer domain. The diffusive layer and the outer turbulent region are, thus, conceptually discussed in different studies, based on different points of view. However, experimental studies directed to estimate the "boundary" between these layers without using pre-defined profiles are still needed. A description of interfacial transfer that uses a random square wave, representing patches of liquid having alternately high or low gas concentration, is presented here. Statistical properties of concentration fields are deduced without pre-defining a concentration profile. The way to express different normalized profiles for mass transfer by using the random square wave is demonstrated. The influence of diffusion on the profiles is discussed, together with their main characteristics. Further, experimental results are presented, in which oxygen and water were chosen to form the gas-liquid system. The experimental data are compared with the theoretical predictions, showing that the boundary between the layers is well defined and that the relevance of diffusion effects along the vertical axis can be well quantified.

\section{NORMALIZED PROFILES OF MASS CONCENTRATION}

The region of interest of the present study is the mean concentration boundary layer. Mathematically, the boundary layer is a narrow region where the solution of a differential equation for the concentration changes rapidly (Bender and Orszag, 1999). For practical purposes, the concentration boundary layer in turbulent flows may be defined as 
the region in which the mean concentration varies from the value at the interface up to the value in the bulk liquid. As the evolution in space is asymptotic, the limit of $1 \%$ is considered here, which means that the boundary layer ends at $\left(\overline{\mathrm{C}}(\delta)-\mathrm{C}_{\mathrm{b}}\right) /\left(\mathrm{C}_{\mathrm{S}}-\mathrm{C}_{\mathrm{b}}\right)=0.01$. $\mathrm{C}_{\mathrm{S}}$ and $\mathrm{C}_{\mathrm{b}}$ are the surface and bulk concentrations of dissolved gas, respectively; $\delta$ is the boundary layer thickness and $\overline{\mathrm{C}}(\delta)$ is the mean concentration at the position $\mathrm{z}=\delta$, where $\mathrm{z}$ is the vertical coordinate with origin at the interface. The region limited by the concentration boundary layer contains all the structure considered in the present study, composed of the diffusive layer (for the mass transport) and the outer turbulent region (for the liquid movement). The diffusive layer is considered as a whole, that is, all the space occupied by the "inner" and "outer" diffusive layers. The limit of the outer diffusive layer is, thus, the frontier between the diffusive layer and the outer turbulent region. The concentration in the bulk liquid is homogeneous, that is, $\overline{\mathrm{C}}(\mathrm{z}>\delta)=\mathrm{C}_{\mathrm{b}}$.

\section{Random Square Wave}

Figure 1 shows a scheme of the superficial concentration boundary layer and the fluid patches considered for the random square wave. The present arguments expand the description of Schulz and Schulz (1991), who considered a situation without effects of diffusion.

Assuming no effects of diffusion, the time evolution of the concentration $\mathrm{C}$ in the boundary layer may be sketched as presented by Figure 2 . $\mathrm{C}$ alternates between the values $\mathrm{C}_{\mathrm{s}}$ (at the surface) and $\mathrm{C}_{\mathrm{b}}$ (in the bulk liquid), forming a random square wave signal.

Diffusion has a rounding effect on the edges of the square wave, a result of the mass exchange between regions with different concentrations. For small patches of fluid, it results in significant changes in the value of $\mathrm{C}$, lowering high values and increasing low values. Figure 3(a) shows oxygen concentration fluctuations measured by Janzen (2006) using a microprobe (Janzen et al., 2008), evidencing that the amplitude of the oscillations is lower than $\mathrm{C}_{\mathrm{s}}-\mathrm{C}_{\mathrm{b}}$. Similar results can be found in Herlina and Jirka (2008), who used optical techniques. To take diffusion into account in random square waves, it is necessary to reduce the maximum value (represented by $\mathrm{C}_{\mathrm{s}}-\mathrm{S}$ ) and increase the minimum value (represented by $\mathrm{C}_{\mathrm{b}}+\mathrm{B}$ ). $\mathrm{S}$ and $\mathrm{B}$ depend on $\mathrm{z}$. Figure 2 is then replaced by Figure 3(b), where $\mathrm{S}$ and $\mathrm{B}$, the parcels that reduce the amplitude of the oscillations, are shown.
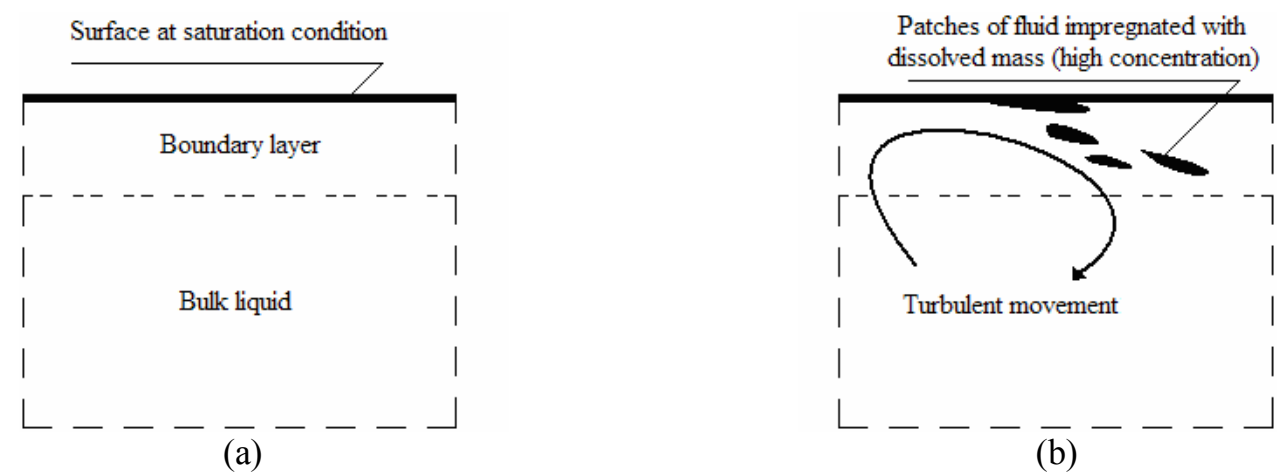

Figure 1: a) Concentration boundary layer at the interfacial region. b) Patches of fluid transported by turbulent movement.

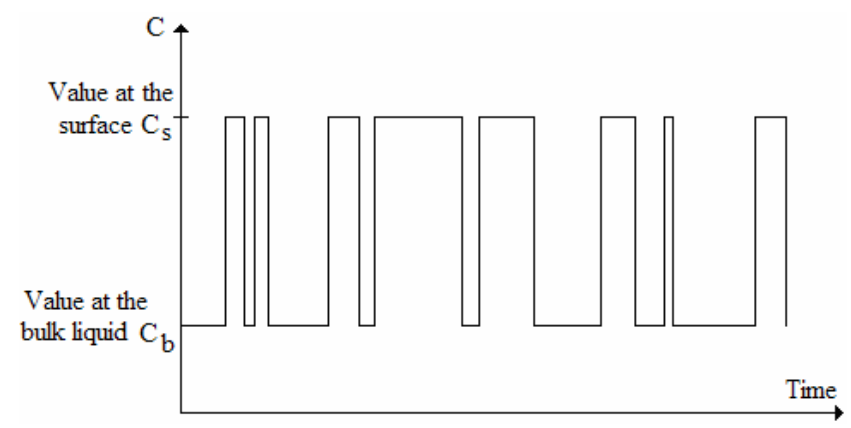

Figure 2: Square wave evolution of $\mathrm{C}$ within the boundary layer 


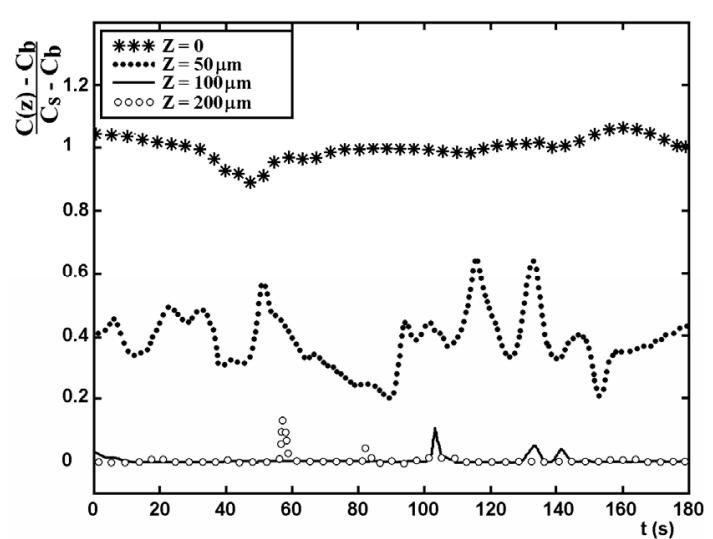

(a)

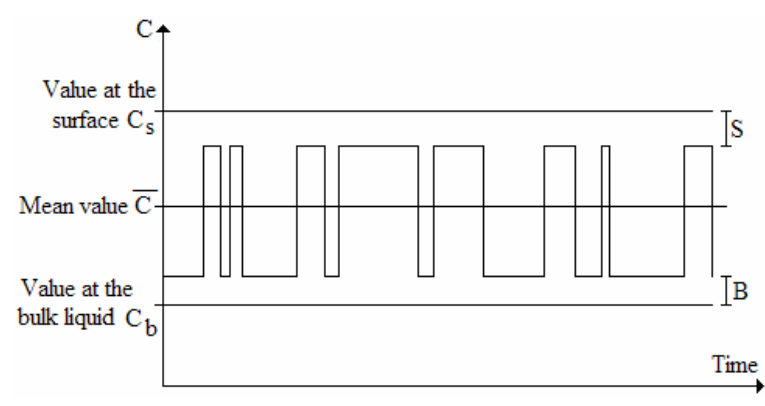

(b)

Figure 3: a) Measurements of oxygen concentration fluctuations (Janzen, 2006, Janzen et al., 2008). b) Evolution of C in the boundary layer, considering a mean reduction $S$ of $C_{s}$ and a mean increasing $B$ of $\mathrm{C}_{b}$.

Defining $\mathrm{n}$ for a point in the boundary layer as

$\mathrm{n}=\frac{\text { Time with }\left(\mathrm{C}_{\mathrm{S}}-\mathrm{S}\right)}{\text { Total time of the observation }}$

It implies that

$$
1-\mathrm{n}=\frac{\text { Time with }\left(\mathrm{C}_{\mathrm{b}}+\mathrm{B}\right)}{\text { Total time of the observation }}
$$

Taking mass conservation into account:

$\mathrm{B}=\frac{\mathrm{Sn}}{(1-\mathrm{n})}$

$\mathrm{n}$ is a function of $\mathrm{z}$, the distance to the surface. Equations 1 through 3 conduce to the mean concentration of $\mathrm{C}(\mathrm{z})$, denoted by $\overline{\mathrm{C}}(\mathrm{z})$, given by:

$$
\overline{\mathrm{C}}(\mathrm{z})=\mathrm{nC}_{\mathrm{s}}+(1-\mathrm{n}) \mathrm{C}_{\mathrm{b}}
$$

Rearranging the terms of Eq. 4, the normalized form of $\overline{\mathrm{C}}(\mathrm{z})$ is given by:

$$
\mathrm{n}=\frac{\overline{\mathrm{C}}(\mathrm{z})-\mathrm{C}_{\mathrm{b}}}{\mathrm{C}_{\mathrm{s}}-\mathrm{C}_{\mathrm{b}}}
$$

That is, the function $n$ defined by Eq. 1 is also the normalized form of $\overline{\mathrm{C}}(\mathrm{z})$.

Figure 3(b) shows that $\mathrm{S}$ is lower than $\mathrm{C}_{\mathrm{s}}-\overline{\mathrm{C}}$. A reduction coefficient $\alpha$ is then defined as:

$$
\left.\begin{array}{ll}
\mathrm{S}=\alpha\left(\mathrm{C}_{\mathrm{s}}-\overline{\mathrm{C}}\right) & 0 \leq \alpha \leq 1 \\
\text { or, in this case, (eq.4) } & \\
\mathrm{S}=\alpha(1-\mathrm{n})\left(\mathrm{C}_{\mathrm{s}}-\mathrm{C}_{\mathrm{b}}\right) & 0 \leq \alpha \leq 1
\end{array}\right\}
$$

$\alpha$ is a function of $z$. The instantaneous fluctuations of $\mathrm{C}(\mathrm{z})$ around $\overline{\mathrm{C}}(\mathrm{z})$ are denoted by $\mathrm{c}(\mathrm{z})$. Two fluctuations (positive and negative) may be calculated for the square wave:

$$
\begin{aligned}
& \mathrm{c}_{1}(\mathrm{z})=(1-\mathrm{n})\left(\mathrm{C}_{\mathrm{s}}-\mathrm{C}_{\mathrm{b}}\right)(1-\alpha) \text { (positive) } \\
& \mathrm{c}_{2}(\mathrm{z})=-\mathrm{n}\left(\mathrm{C}_{\mathrm{s}}-\mathrm{C}_{\mathrm{b}}\right)(1-\alpha) \quad \text { (negative) }
\end{aligned}
$$

The mean square of $\mathrm{c}(\mathrm{z})$ is given by $c^{2}(z)=\overline{[C(z)-\bar{C}(z)]^{2}}$. The random square wave description conduces readily to:

$$
\begin{aligned}
& \overline{\mathrm{c}^{2}(\mathrm{z})}=\left\{\mathrm{C}_{\mathrm{s}}-\mathrm{S}-\left[\mathrm{nC}_{\mathrm{s}}+(1-\mathrm{n}) \mathrm{C}_{\mathrm{b}}\right]\right\}^{2} \\
& \mathrm{n}+\left\{\mathrm{C}_{\mathrm{b}}+\mathrm{B}-\left[\mathrm{nC}_{\mathrm{s}}+(1-\mathrm{n}) \mathrm{C}_{\mathrm{b}}\right]\right\}^{2}(1-\mathrm{n})
\end{aligned}
$$

Using Eqs. 3 and 6b in Eq. 9 and rearranging the terms, the normalized form of the rms value of $\mathrm{c}(\mathrm{z})$, $\sqrt{\overline{\mathrm{c}^{2}(\mathrm{z})}} /\left(\mathrm{C}_{\mathrm{S}}-\mathrm{C}_{\mathrm{b}}\right)$, is given by:

$\frac{\sqrt{\overline{\mathrm{c}^{2}(\mathrm{z})}}}{\mathrm{C}_{\mathrm{s}}-\mathrm{C}_{\mathrm{b}}}=\mathrm{c}^{\prime}=(1-\alpha) \sqrt{\mathrm{n}(1-\mathrm{n})}$ 
c' depends on $\mathrm{n}$ and $\alpha$. For a situation without diffusion $(\alpha=0)$, if the function $\mathrm{n}$ is known, then the function c' is also known.

\section{Characteristics of $\mathbf{n}$ and $\mathbf{c}^{\prime}$ - Boundary Between Surface and Bulk Liquid Influenced Regions}

The function $\mathrm{n}$ (Eq. 5) varies in the range 0-1. The general form of $\mathrm{n}$ is unknown, but experience shows that it presents monotonic behavior, either increasing or decreasing close to the interface (depending on the direction of the mass transfer). In other words, $\mathrm{dn} / \mathrm{dz}$ does not equal zero within the region of interest. Measurements right at the surface $(\mathrm{z}=0)$ are difficult, but it is generally assumed that the maximum value of $d n / d z$ occurs at $z=0$.

Considering the function c' defined by Eq. 10 without diffusive effects $(\alpha=0)$, the first derivative furnishes:

$$
\frac{\mathrm{dc}^{\prime}}{\mathrm{dz}}=\frac{1-2 \mathrm{n}}{2 \sqrt{\mathrm{n}(1-\mathrm{n})}} \frac{\mathrm{dn}}{\mathrm{dz}}
$$

Equation 11 shows that $\mathrm{c}^{\prime}=\sqrt{\mathrm{n}(1-\mathrm{n})}$ presents a peak amplitude of 0.5 at $n=0.5$.

Considering now Eq. 10 with diffusive effects, it contains $\sqrt{\mathrm{n}(1-\mathrm{n})}$ multiplied by $(1-\alpha)<1$. Thus, diffusive effects impose peak amplitudes lower than 0.5 . The peak position (denoted here by $p_{c}$ ) separates the regions with preferential influence from the surface or from the bulk liquid. Between the peak and the position where $n=1$, the mass transfer and the characteristics of related profiles are mainly influenced by the surface (where molecular diffusion is more relevant), while between the peak and the position where $n=0$, they are mainly influenced by the bulk liquid (where turbulent transport is more relevant). Equation 10 agrees with the general results of the literature, furnishing $c^{\prime}=0$ at the surface and in the bulk liquid.

\section{The Reduction Coefficient Function $\alpha$}

Equations 6 define $\alpha$ as a measure of the effect of diffusion over the $\mathrm{C}$ records. A value of $\alpha$ close to 1 indicates strong influence of diffusion while a value close to 0 indicates weak influence of diffusion. As mentioned, it is generally accepted that molecular diffusion governs mass transfer at the surface. Turbulent influences are rare or not present (see Fig. 3).
This fact is captured by the $\mathrm{C}$ records, and a higher value of $\alpha$ (close to 1 ) is expected very near the surface. At some distance under the surface (intermediate region), alternating values of $\mathrm{C}$ dominate the concentration records (Fig. 3). Concentrations more representative of the bulk liquid ascend up to the surface, while concentrations more representative of the surface sink down into the bulk liquid. An approximate description would be a "random counter-current flow". Although diffusion always affects the recorded values, the transit time through this intermediate region is too short to homogenize the mixture. Consequently, the records are more influenced by the macroscopic turbulent movement of patches with distinct concentrations, and a lower value of $\alpha$ (between 0 and 1) is expected. Farther from the surface, the mixture produced by turbulent movements (turbulent diffusion) is superimposed by the homogenization at the molecular level produced by molecular diffusion (which allows one to use a reference value $\mathrm{C}_{\mathrm{b}}$ for the bulk liquid). In this situation, a higher value of $\alpha$ (close to 1) is again expected. Thus, the function that describes the coefficient $\alpha$ has a minimum peak (whose position is denoted here by $p_{\alpha}$ ) in the intermediate region.

\section{Complementary Aspects of the Different Profiles}

The peaks of c' and $\alpha$ evidence different aspects of the subsuperficial concentration field. While the maximum peak of c' separates regions of main influence of the surface (molecular diffusion) or the bulk liquid (turbulent transport), the minimum peak of $\alpha$ defines the region where patches of fluid with different concentrations are still not homogenized through diffusion mechanisms. Thus, the peak of $\alpha$ can not occur closer to the surface than the peak of c' (otherwise, turbulent movements would prevail within the molecular diffusive region, which would be a contradiction). Experimental evidence of this affirmation is needed to confirm the adequacy of the use of $p_{c}$ as a measure of the diffusive layer (considering, for example, the numerical results of Maganaudet and Calmet, 2006). The present study furnishes experimental confirmation of the complementary aspect of the different mentioned profiles, (1) supporting the use of the peak of c' as the boundary between regions of molecular and turbulent influences, and (2) quantifying the relevance of diffusion through the reduction coefficient function $\alpha$. 


\section{EXPERIMENTAL SETUP}

Experiments on oxygen absorption by water were conduced by Janzen (2006) at the Institute of Hydromechanics, University of Karlsruhe, Germany. The data permitted description of the mean characteristics of the oxygen concentration in the liquid phase very close to the surface and a check on the theoretical concepts previously described.

Figure 4 shows a sketch of the turbulencegenerating system composed of a tank made of Perspex, with a $0.50 \mathrm{~m} \times 0.50 \mathrm{~m}$ square cross-section and $0.65 \mathrm{~m}$ height. Water was filled until a depth of $48.0 \mathrm{~cm}$. For the concentration field experiments, a $6.25 \mathrm{~cm}$ mesh size (M) was selected, resulting in a solidity of $36 \%$. The center of oscillation of the grid was positioned $28.0 \mathrm{~cm}$ under the surface. Full descriptions of this oscillating-grid tank may be found in Herlina (2005) and Janzen (2006). The grid was operated with strokes $\mathrm{S}$ of $5.0 \mathrm{~cm}$ and $8.0 \mathrm{~cm}$ and the frequency $\mathrm{f}$ was varied from 1.2 to $5.0 \mathrm{~Hz}$. The mean water temperature was $26.5^{\circ} \mathrm{C}$ for $\mathrm{S}=5.0 \mathrm{~cm}$ and $24.6^{\circ} \mathrm{C}$ for $\mathrm{S}=8.0 \mathrm{~cm}$. Table 1 presents experimental parameters, where Re is the Reynolds number for the equipment. The frequency ranges for both strokes were chosen based on the quality of the recorded images, to assure a high quality for the calculated statistical functions. The runs were performed sequentially (to approach similar environmental and surface conditions), with unbroken and visually clean surfaces. Data acquisition began $10 \mathrm{~min}$ after the onset of oscillation.

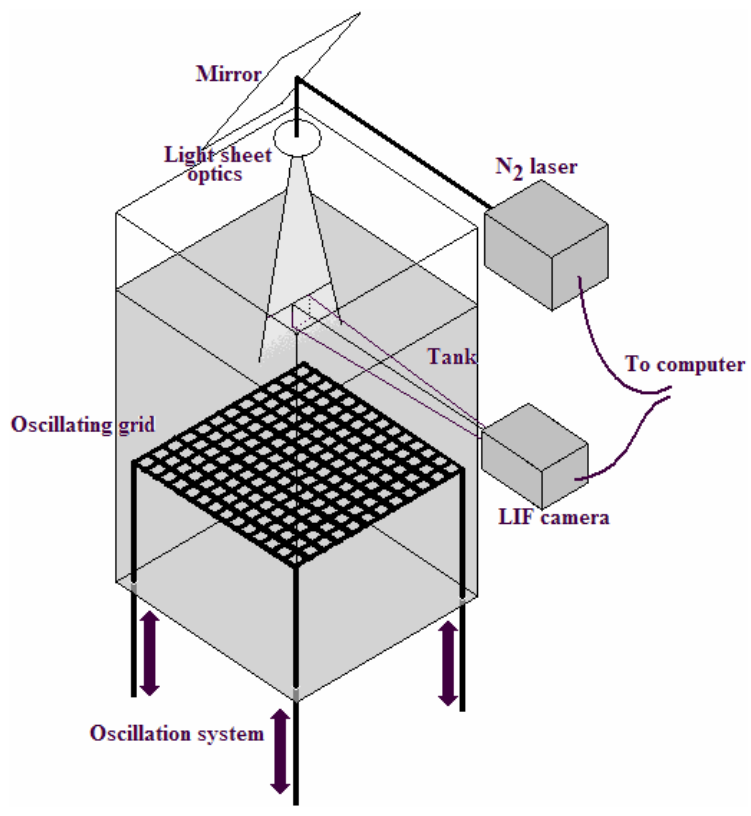

Figure 4: Oscillating-grid tank and experimental setup for the concentration field experiments.
Table 1: Experimental settings for the oxygen transfer runs.

\begin{tabular}{|c|c|c|c|c|c|}
\hline $\begin{array}{c}\text { Run } \\
\text { Number }\end{array}$ & $\mathbf{f}(\mathbf{H z})$ & $\mathbf{S}(\mathbf{c m})$ & $\mathbf{M}(\mathbf{c m})$ & $\mathbf{T}\left({ }^{\mathbf{0}} \mathbf{C}\right)$ & $\begin{array}{c}\mathbf{R e}=\mathbf{f} \\
\mathbf{S}^{2} / \mathbf{v}\end{array}$ \\
\hline 1 & 2 & 5.0 & 6.25 & 26.5 & $5.7910^{3}$ \\
2 & 3 & 5.0 & 6.25 & 26.5 & $8.6910^{3}$ \\
3 & 4 & 5.0 & 6.25 & 26.5 & $11.610^{3}$ \\
4 & 5 & 5.0 & 6.25 & 26.5 & $14.510^{3}$ \\
5 & 1.2 & 8.0 & 6.25 & 24.6 & $8.5110^{3}$ \\
6 & 2.2 & 8.0 & 6.25 & 24.6 & $15.610^{3}$ \\
7 & 2.7 & 8.0 & 6.25 & 24.6 & $19.110^{3}$ \\
8 & 3.2 & 8.0 & 6.25 & 24.6 & $22.710^{3}$ \\
\hline
\end{tabular}

The laser-induced fluorescence (LIF) technique using pyrene butyric acid (PBA) was used. PBA, which fluorescence changes in the presence of oxygen, was used to determine the dissolved oxygen concentration in water, as described by Vaughan and Weber (1970).

Figure 4 shows the LIF setup used in this study. For the experiments, the tank was filled with water and $2 \times 10^{-5} \mathrm{M}$ PBA. Nitrogen was bubbled into the water during 20 minutes to attain an oxygen concentration of about $0.7 \mathrm{mg} / \mathrm{l}$. A pulsed nitrogen laser (MNL 801) with a mean energy power of $0.4 \mathrm{~mJ}$ and an emission wavelength of $337.1 \mathrm{~nm}$ was used to excite the PBA solution, which fluoresces between $370-410 \mathrm{~nm}$. The laser beam was guided into the centre of the tank through a UV-mirror and a combination of lenses. A FlowMaster CCD camera (1024 x 1280 pixels and 12 bit), with a macro objective was used to obtain images of approximately $9.5 \mathrm{~mm} \times 11.9 \mathrm{~mm}$ from a distance of about $30 \mathrm{~cm}$, allowing a resolution of approximately $9 \mu \mathrm{m}$. Nine hundred images were taken for each run, in three sets of 300 images. Image processing was performed, involving noise removal, water surface detection, correction of laser attenuation, and correction of optical blurring near the interface. The image processing procedure is described in details by Janzen (2006), being the same of that described by Woodrow and Duke (2001) and Herlina and Jirka (2004).

\section{RESULTS}

\section{c' Profiles}

The c' profiles of the oxygen concentration are presented in Figure 5(a). All profiles show a well defined peak. Steep slopes are observed close to the surface and long tails after the peak. The vertical axis is normalized with the c'-peak coordinate, that is, $\mathrm{z}^{+}=\mathrm{z} / \mathrm{p}_{\mathrm{c}}$. Figure $5(\mathrm{~b})$ shows that the measured values of $p_{c}$ varied in the range from 264 to $404 \mu$, decreasing for higher Reynolds number (or, in other 
words, presenting c'-peaks closer to the surface). This behavior agrees with the general understanding that the thickness of the "diffusive region" close to the surface must be lower for higher agitation levels of the liquid. The experimental amplitudes of the peaks vary in the range from 0.13 to 0.17 , which are lower than 0.5 (in agreement with the theoretical prediction). Peaks of c' were also reported by several authors: Lee and Luk (1982) presented values in the range of about 0.05 to 0.3; Chu and Jirka (1992) presented a peak value of about 0.12; Atmane and George (2002) presented values in the range of about 0.2 to 0.3 ; Herlina (2005) presented values in the range of 0.14 to 0.17; Magnaudet and Calmet (2006) presented values in the range of about 0.28 to 0.35 (for different Schmidt numbers). As can be seen, all reported values are lower than the proposed limit of 0.5 .

\section{n Profiles}

Figure 6(a) shows the normalized mean oxygen concentration profiles $\mathrm{n}$ (see Eq. 5) along the $\mathrm{z}$ axis, while Figure 6(b) shows the same profiles plotted against the normalized axis, $\mathrm{z}^{+}=\mathrm{z} / \mathrm{p}_{\mathrm{c}}$. All measured curves merged together, showing that $p_{c}$ is a good choice to normalize the mean concentration profiles. Figure 6(c) shows predictions of $\mathrm{n}$ following Münsterer and Jähne (1998), who used the surface renewal and the small eddy models scaled with powers of the Schmidt number. Figure 6(c) also reproduces the data of Figure 6(b), to permit comparisons. Predictions marked with (a) are for $\mathrm{Sc}^{1 / 2}$ and with (b) for $\mathrm{Sc}^{2 / 3}$. Münsterer and Jähne (1998) defined $\mathrm{z}+=\left[\left.\mathrm{z}(\mathrm{dC} / \mathrm{dz})\right|_{\mathrm{z}=0} /\left(\mathrm{C}_{\mathrm{s}}-\mathrm{C}_{\mathrm{b}}\right)\right]$ and showed experimental data closer to the predictions for $\mathrm{Sc}^{2 / 3}$, also observed in the present study, despite the different definitions of $\mathrm{z}^{+}$. Figures 6(d) and 6(e) show that the measured values of the boundary layer thickness, $\delta$, varied in the range from $0.8810^{3}$ to $1.3610^{3} \mu$, decreasing for higher Reynolds number. The ratio $\mathrm{p}_{\mathrm{c}} / \delta$ has a mean value of about 0.30 , showing that around $30 \%$ of the concentration

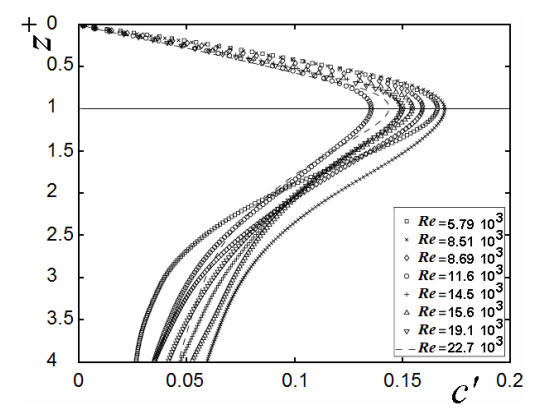

(a) boundary layer is mainly affected by the surface, while the remaining $70 \%$ are mainly affected by the bulk liquid.

\section{$\alpha$ Profiles}

As the profiles for $\mathrm{n}$ and c' are known (experimentally determined), Eq. 10 was used to calculate the coefficient function $\alpha$. Figure 7(a), with the vertical axis normalized as $\mathrm{z}+=\mathrm{z} / \mathrm{p}_{\mathrm{c}}$ shows that $\alpha$ varied in the range of around 0.2 to 1 , being very sensitive to agitation conditions. Figure 7(b) shows that the peak values decreased strongly, from 0.59 to 0.21 , upon increasing the Reynolds number. The horizontal line $z^{+=1}$ in Figure 7 (a) shows that all peaks of $\alpha$ occur at $z^{+}>1$ (that is, $p_{\alpha}>p_{c}$ ) and that the c'-peaks and $\alpha$-peaks are more separated for higher Reynolds numbers. The ratio $\mathrm{p}_{\alpha} / \mathrm{p}_{\mathrm{c}}$ varies from 1.44 to 2.58 , and its evolution with the Reynolds number is shown in Figure 7(c).

Molecular diffusion is expected to be dominant at $\mathrm{z}^{+}<1$. The values of $\alpha$ closer to $1.0(\sim 0.6<\alpha<\sim 0.95$, shown in Figure $7(\mathrm{a}))$ are in agreement with this expectation. Although the near-surface dominance of molecular diffusion over turbulent transport is amply mentioned in the literature (e.g., Herlina, 2005), a parameter which quantifies this dominance was still not available. The coefficient $\alpha(0<\alpha<1)$ fills this gap. Comparisons between values of molecular and turbulent fluxes were presented by Janzen (2006) and Herlina and Jirka (2008), showing that the present results are consistent with previous observations. As already mentioned, farther from the surface $\left(\mathrm{z}^{+}>\mathrm{p}_{\alpha} / \mathrm{p}_{\mathrm{c}}\right)$, molecular and turbulent diffusion are superimposed and homogenize the concentration to $\mathrm{C}_{\mathrm{b}}$, with $\alpha$ attaining once more values $\alpha>0.6$. The subsuperficial structure composed by a diffusive layer in the region mainly affected by the surface and an outer turbulent region is well evidenced by the present data and analysis. The frontier between both regions is conveniently quantified using the vertical coordinate $\mathrm{p}_{\mathrm{c}}$.

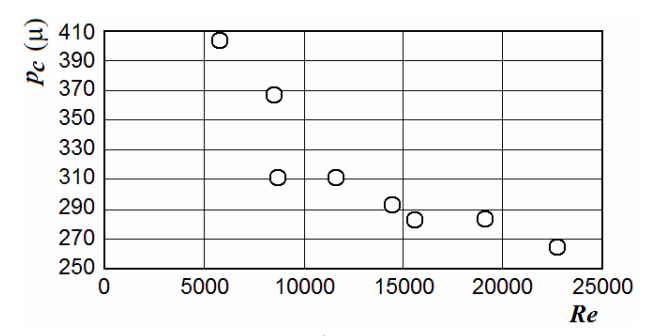

(b)

Figure 5: a) rms profiles of the oxygen concentration fluctuations. b) Measured $p_{c}$ in the range from 264 to $404 \mu$ distant from the interface, plotted against Re. 


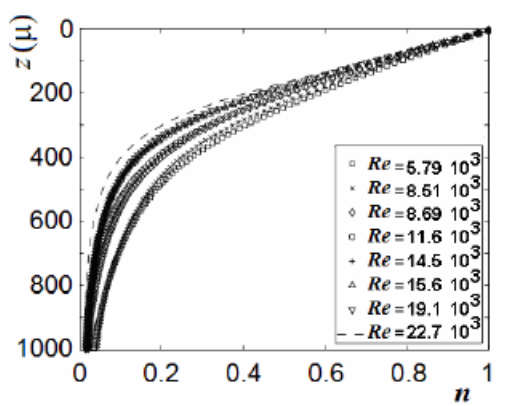

(a)

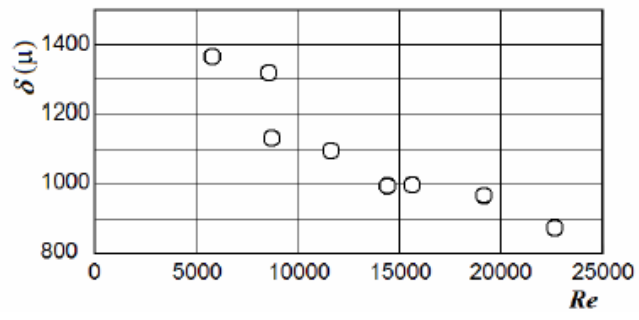

(d)

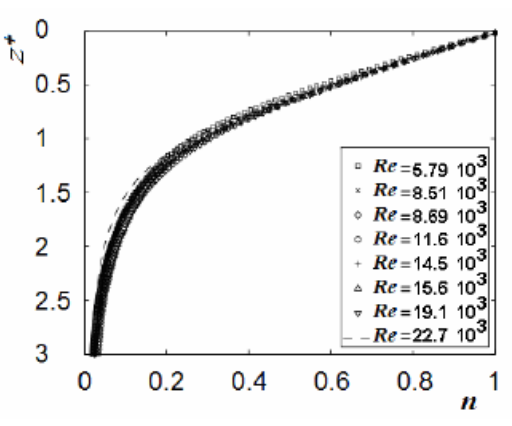

(b)

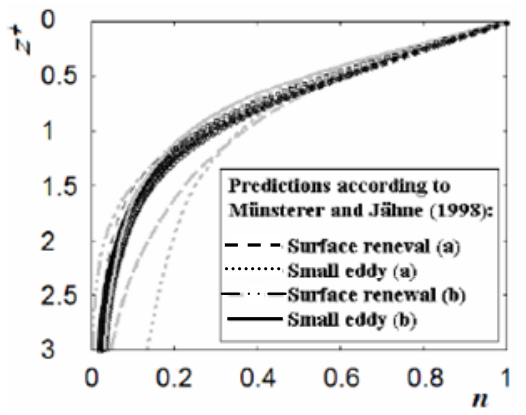

(c)

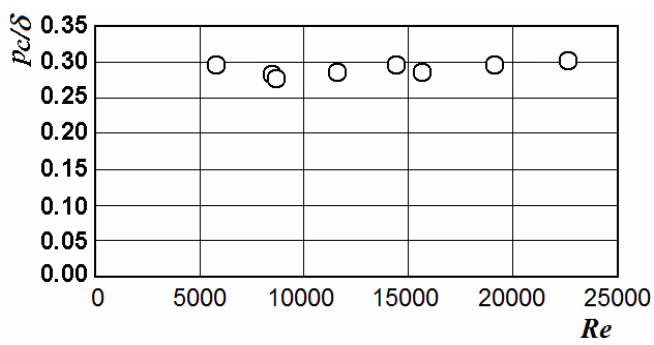

(e)

Figure 6: a) Mean oxygen concentration profiles (n) measured with LIF technique, plotted against a vertical axis without normalization. b) Vertical axis normalized as $\mathrm{z}^{+=}=\mathrm{z} / \mathrm{p}_{\mathrm{c}}$ showing that the profiles merged together. c) Predictions of Münsterer and Jähne (1998) for models scaled with powers of the Schmidt number: (a) scaled with $\mathrm{Sc}^{1 / 2}$ and (b) scaled with $\mathrm{Sc}^{2 / 3}$. d) Boundary layer thicknesses, defined as the position $\delta$ where $\left.\left(\bar{C}(\delta)-C_{B}\right) /\left(C_{S}-C_{B}\right)=0.01 . e\right)$ Ratio $p_{c} / \delta$ showing a mean value around 0.3 .

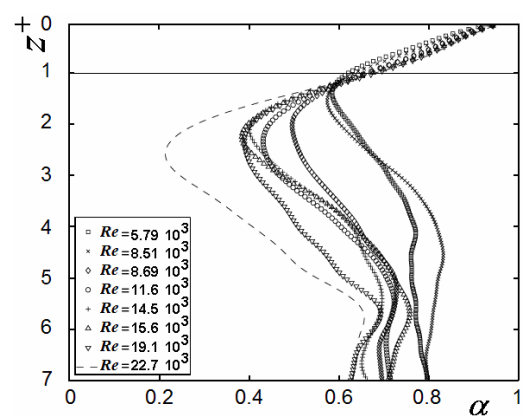

(a)

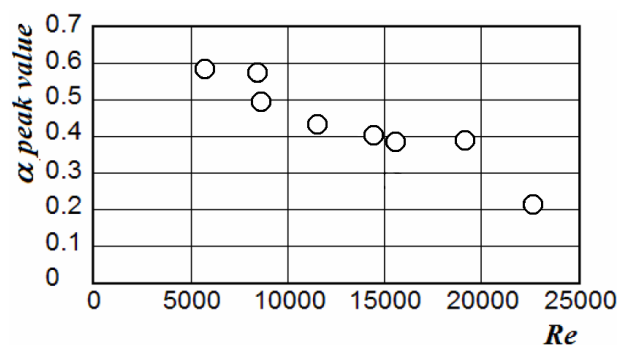

(b)

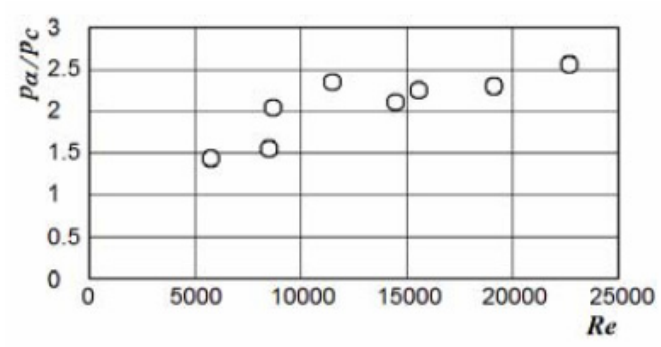

(c)

Figure 7: a) $\alpha$ profiles showing strong dependence on the agitation conditions. b) $\alpha$-peak values decreasing for higher Reynolds number. c) $p_{\alpha} / p_{c}$ values against the Reynolds number. $p_{c} / p_{\alpha}>1$, as expected from theoretical arguments. 


\section{CONCLUSIONS}

It was shown theoretically that the subsurface region of interfacial mass transfer may be adequately described by the random square wave approximation. The effect of diffusion was quantified through the "reduction coefficient" function $\alpha$, and the behavior of the concentration fluctuations through the function c' (rms of the fluctuations), with both functions presenting peaks in the region of interest. It was proposed that the coordinate of the c'-peak $\left(\mathrm{p}_{\mathrm{c}}\right)$ is a measure of the thickness of the diffusive layer, and that the coordinate of the $\alpha$-peak $\left(p_{\alpha}\right)$ occurs where patches of fluid are still not homogenized, leading to the conclusion that $\mathrm{p}_{\alpha}>\mathrm{p}_{\mathrm{c}}$. It was also shown theoretically that the amplitude of the peak of c' must be lower than 0.5 .

The experimental results showed that the position of the peaks of c' $\left(p_{c}\right)$ decreased from $p_{c}=404 \mu$ to $p_{c}$ $=264 \mu$ when increasing the Reynolds number from $5.7910^{3}$ to $22.710^{3}$. The amplitudes of the peaks of c' oscillated in the range from 0.13 to 0.17 , thus lower than the theoretical limit of 0.5 . The peaks of $\alpha$ occurred at positions $\mathrm{p}_{\alpha}>\mathrm{p}_{\mathrm{c}}$, confirming the expectations from the theoretical arguments. The ratio $\mathrm{p}_{\alpha} / \mathrm{p}_{\mathrm{c}}$ varied from 1.44 to 2.58 for the present experimental conditions, showing that $\mathrm{p}_{\mathrm{c}}$ may be used as a measure of the diffusive layer. The amplitude of the $\alpha$-peaks decreased from 0.59 to 0.21 upon increasing the Reynolds number. Close to the surface $\left(\mathrm{z}^{+}<1\right) \alpha$ attained values closer to $1(\sim 0.6<\alpha<\sim 0.95)$, indicating a greater influence of diffusion in this region. The effects of diffusion along $\mathrm{z}$ could be conveniently interpreted through the function $\alpha$.

\section{NOMENCLATURE}

\begin{tabular}{|c|c|c|}
\hline$\alpha$ & $\begin{array}{l}\text { reduction coefficient } \\
\text { function }\end{array}$ & nondimensional \\
\hline$\alpha_{1}$ & proportionality coefficient & nondimensional \\
\hline$\alpha_{2}$ & proportionality coefficient & nondimensional \\
\hline$\delta$ & boundary layer thickness & \\
\hline$\delta_{1}$ & $\begin{array}{l}\text { thickness of the internal } \\
\text { diffusive layer }\end{array}$ & \\
\hline$\delta_{2}$ & $\begin{array}{l}\text { thicknesses of the external } \\
\text { diffusive layer }\end{array}$ & \\
\hline$v$ & kinematic viscosity & $\mathrm{m}^{2} / \mathrm{s}$ \\
\hline B & $\begin{array}{l}\text { increase of the bulk liquid } \\
\text { concentration }\end{array}$ & $\mathrm{kg} / \mathrm{m}^{3}$ \\
\hline $\mathrm{c}_{1}$ & $\begin{array}{l}\text { positive concentration } \\
\text { fluctuation }\end{array}$ & $\mathrm{kg} / \mathrm{n}$ \\
\hline$c_{2}$ & $\begin{array}{l}\text { negative concentration } \\
\text { fluctuation }\end{array}$ & $\mathrm{kg} / \mathrm{r}$ \\
\hline
\end{tabular}

\begin{tabular}{|c|c|c|}
\hline c' & RMS of the concentration & $\mathrm{kg} / \mathrm{m}^{3}$ \\
\hline & ion of $z$ ) & \\
\hline $\mathrm{C}_{\mathrm{S}}$ & dissolved gas concentration & $\mathrm{kg} / \mathrm{m}^{3}$ \\
\hline $\mathrm{C}_{\mathrm{B}}$ & $\begin{array}{l}\text { dissolved gas concentration } \\
\text { in the bulk liquid }\end{array}$ & $\mathrm{kg} / \mathrm{m}^{3}$ \\
\hline$\overline{\mathrm{C}}(\delta)$ & $\begin{array}{l}\text { mean concentration at the } \\
\text { position } z=\delta\end{array}$ & $\mathrm{kg} / \mathrm{m}^{3}$ \\
\hline ( & $\begin{array}{l}\text { molecular diffusivity of the } \\
\text { compound being } \\
\text { transported in the liquid }\end{array}$ & $\mathrm{m}^{2} / \mathrm{s}$ \\
\hline & $\begin{array}{l}\text { oscillation frequency of the } \\
\text { grid }\end{array}$ & $\mathrm{Hz}$ \\
\hline C & $\begin{array}{l}\text { characteristic length scale } \\
\text { at the interface }\end{array}$ & $\mathrm{m}$ \\
\hline$\Lambda$ & $\begin{array}{l}\text { mesh size (side of a square } \\
\text { cell) }\end{array}$ & $\mathrm{m}$ \\
\hline & $\begin{array}{l}\text { normalized mean } \\
\text { concentration (function of } \mathrm{z} \text { ) }\end{array}$ & nondimensional \\
\hline $\mathrm{p}_{\alpha}$ & $\begin{array}{l}\text { position of the minimum } \\
\text { peak of the reduction } \\
\text { coefficient function } \alpha\end{array}$ & $\mathrm{m}$ \\
\hline c & $\begin{array}{l}\text { position of the peak of the } \\
\text { function c' }\end{array}$ & $\mathrm{m}$ \\
\hline $\mathrm{Re}_{\mathrm{s}}=\mathrm{uL}$ & $\begin{array}{l}\text { Reynolds number at the } \\
\text { surface }\end{array}$ & nondimensional \\
\hline $\mathrm{Re}=\mathrm{f} \mathrm{S} / \mathrm{v}$ & $\begin{array}{l}\text { Reynolds number of the } \\
\text { equipment }\end{array}$ & nondimensional \\
\hline $\mathrm{S}$ & $\begin{array}{l}\text { reduction of the saturation } \\
\text { concentration }\end{array}$ & $\mathrm{kg} / \mathrm{m}^{3}$ \\
\hline $\mathrm{Sc}=v / \mathrm{D}$ & Schmidt number & nondimensional \\
\hline $\mathrm{S}_{\mathrm{k}}$ & stroke of the grid & $\mathrm{m}$ \\
\hline & characteristic velocity sca & $\mathrm{n} / \mathrm{s}$ \\
\hline & vertical coordinate & $\mathrm{n}$ \\
\hline
\end{tabular}

\section{ACKNOWLEDGEMENTS}

The authors are indebted to FAPESP, CNPq and CAPES (process 2201/06-2), Brazilian research support foundations, for the support of this study; and to the Institute of Hydromechanics, University of Karlsruhe, Germany.

\section{REFERENCES}

Atmane, M. A. and George, J., Gas transfer across a zero-shear surface: a local approach. In: Gas Transfer at Water Surfaces, American Geophysical Union, Geophysical Monograph, 127, p. 255-259 (2002).

Bender, C. M. and Orszag, S. A., Advanced 
Mathematical Methods for Scientists and Engineers, Asymptotic Methods and Perturbation Theory, Springer Science+Business Media, USA (1999).

Calmet, I. and Magnaudet, J., Large-eddy simulation of high-Schmidt number mass transfer in a turbulent channel flow, Phys. Fluids, 9, p. 438-455 (1997).

Chu, C. and Jirka, G., Turbulent gas flux measurements below the air-water interface of a grid-stirred tank, International Journal of Heat and Mass Transfer, v. 35, p. 1957-1968 (1992).

Germano, M., A proposal for a redefinition of the turbulent stresses in the filtered Navier-Stokes equations, Phys. Fluids, 29, p. 2323-2324 (1986).

Handler, R. A., Saylor, J. R., Leighton, R. I. and Rovelstad, A. L., Transport of a passive scalar at a shear-free boundary in fully turbulent open channel flow, Phys. Fluids, 11, p. 2607-2625 (1999).

Herlina, Gas transfer at the air-water interface in a turbulent flow environment, $151 \mathrm{p}$. Doktor Thesis, University of Karlsruhe, Karlsruhe (2005).

Herlina and Jirka, G., Application of LIF to investigate gas transfer near the air-water interface in a grid-stirred tank, Exp. Fluids., Vol. 37, p. 341-349 (2004).

Janzen, J. G., Fluxo de massa na interface ar-água em tanques de grades oscilantes e detalhes de escoamentos turbulentos isotrópicos (mass fluxes at air-water interfaces in tanks with oscillating grids and details of isotropic turbulence), $170 \mathrm{p}$. Tese (Doutorado), Universidade de São Paulo, São Carlos, (2006).

Janzen, J. G., Schulz, H. E. and Lamon, A. W., Medidas de concentração de oxigênio na superfície da água (measurements of dissolved oxygen concentration at water surfaces). Eng. Sanit. Ambient., Vol.13, n. 3, p. 278-273 (2008).

Kumar, S., Gupta, R. and Banerjee, S., An experimental investigation of the characteristics of free-surface turbulence in channel flow, Phys. Fluids 10, p. 437-456 (1998).

Komori, S., Nagaosa, R., Murakami, Y., Chiba, S. and Kuwahara, K. Direct numerical simulation of three-dimensional open-channel flow with zeroshear gas-liquid interface, Phys. Fluids A 5, p. 115-125 (1993).

Lam, K. and Banerjee, S., On the conditions of streak formation in a bounded turbulent flow, Phys. Fluids, A 4, p. 306-320 (1992).

Lee, Y. H. and Luk, S., Characterization of Concentration Boundary Layer in Oxygen Absorption, Ind. Eng. Chem. Fundam., Vol 21, n. 4 , p. 428-434 (1982).
Lewis, W. and Whitman, W., Principles of gas absorption. Industrial and Engineering Chemistry, v. 16, n. 12 , p. 1215-1220 (1924).

Magnaudet, T. and Calmet, I., Turbulent mass transfer through a flat shear-free surface, J. Fluid Mech., Vol. 553, p. 155-185 (2006).

Momesso, A. M., Cunha, A. C., Schulz, S. A. G. and Schulz, H.,E., Harmful gas desorption and oxygen absorption by water bodies, Proceedings of the XXVI International Congress of Limnology - 95, Sao Paulo, p. 369-372 (1997).

Münsterer, T. and Jähne, B., LIF measurements of concentrations profiles in the aqueous mass boundary layer, Experiments in Fluids 25, p. 190196 (1998).

Nagoaosa, R., Direct numerical simulation of vortex structures and turbulent scalar transfer across a free surface in a fully developed turbulence. Phys. Fluids 11, p. 1681-1595 (1999).

Ramshankar, R. and Gollub, J. P., Transport by capillary waves, Part II. Scalar dispersion and the structure of the concentration field, Phys. Fluids A., 3, p. 1344-1350 (1991).

Saylor, J. R. and Handler, R. A., Gas transport across an air/water interface populated by capillary waves, Phys. Fluids, 9, p. 2529-2541 (1999).

Schulz, H. E and Schulz, S. A. G., Modelling belowsurface characteristics in water reaeration, In: Water pollution, modelling, measuring and prediction. Southampton: Computational Mechanics Publications and Elsevier Applied Science, p. 441-454 (1991).

Schulz, H. E., Momesso, A. M., Cunha, A. C. and Schulz, S. A. G., Experimental verification of airwater gas transfer predictions for water pollution, In: Water pollution IV-modelling, measuring and prediction, Bled. Computational Mechanics Publications, p. 391-400 (1997).

Vaughan, W. and Weber, G., Oxygen quenching of pyrenebutyric acid fluorescence in water - a dynamic probe of the microenvironment, Biochemistry, v. 9, n. 3, p. 464-473 (1970).

Woodrow, P. and Duke, S., Laser-induced fluorescence studies of oxygen transfer across unsheared flat and wavy air-water interfaces, Ind. Eng. Chem. Res., v. 40, n. 8, p. 1985-1995 (2001).

Woodrow, P. T. Jr. and Duke, S.R., LIF measurements of oxygen concentration gradients along flat and wavy air-water interfaces. In: Donelan, M.A., Drennan, W.M., Saltzman, E.S., Wannikhof, R., (eds.) Gas Transfer at Water Surfaces, Geophysical Monograph, 127, p. 83-88 (2002).

Zang, Y., Street, R. L. and Koseff, J. R., A dynamic mixed subgrid-scale model and its application to turbulent recirculating flows, Phys. Fluids A., 5, p. 3186-3196 (1993). 